\title{
Psychological Factors to Consider When Adopting an Ethics and Compliance Program
}

\author{
Valeriu Deciu \\ Alexandru Ioan Cuza University, Iasi, Romania \\ Email: deciuvaleriu@gmail.com
}

How to cite this paper: Deciu, V. (2022). Psychological Factors to Consider When Adopting an Ethics and Compliance Program. Psychology, 13, 89-100. https://doi.org/10.4236/psych.2022.131007

Received: October 28, 2021

Accepted: January 21, 2022

Published: January 24, 2022

Copyright $\odot 2022$ by author(s) and Scientific Research Publishing Inc. This work is licensed under the Creative Commons Attribution International License (CC BY 4.0).

http://creativecommons.org/licenses/by/4.0/

\section{(c) (i) Open Access}

\begin{abstract}
Ethics and compliance programs are imperative for all types of business organizations. That is because they ensure that businesses operate according to the demands of the law, and that they maintain their reputation among their customer bases. For instance, ethics and compliance programs may require organizations to conduct external audits on their financial information every once in a while, to ascertain that they are compliant with financial fair play regulations. As such, it is important for businesses to ensure their human power follows the ethical and compliance guidelines to avoid any legal or reputational issues. For businesses to ensure that their employees are compliant, it is important for them to consider the psychological factors that influence human behavior. That is because they will indicate whether the human factor will remain compliant with the set rules and regulations. In this study, the objective will be to prove that psychological factors are essential when adopting ethics and compliance programs, so as to show the psychological factors for organizations to consider. Ideally, human behavior is significantly influenced by motivation, attitudes, and perception, and these are the factors that the research will focus on analyzing.
\end{abstract}

\section{Keywords}

Ethics, Compliance, Psychological Factors, Motivation, Attitude, Perception

\section{Introduction}

It is impossible to understate the essence of ethics and compliance programs to business organizations. That is because the ethics and compliance programs regulate employee behavior, ensuring the mitigation of operational challenges. Ethics and compliance programs also ensure that the internal stakeholders within a business organization conduct themselves, accordingly, avoiding any compliance 
issues that may jeopardize the reputation of the organization. At the same time, ethics and compliance eliminate potential fraud risks that could negatively affect the financial assets of a business organization. However, when developing ethics and compliance guidelines, it is relevant to consider psychological factors and their impact on human behavior. That is because understanding the psychological factors will determine whether individuals will be willing to follow the ethics and compliance guidelines. The research pays special attention to three main psychological factors that influence human behavior. The factors are motivation, perception, and attitude (Tamir \& Thornton, 2018). The psychological factors influence the willingness of individuals to follow rules and guidelines. Therefore, by analyzing literature on the psychological factors and their impact on human behavior. The study will reveal that it is imperative to consider human behavior in the development of ethics and compliance guidelines.

\section{Background}

Every organization has its unique set of characteristics that influence human behavior. For instance, the culture followed by employees within a work organization may influence their receptiveness to given rules and regulations. Therefore, given that ethics and compliance guidelines are designed to ensure all persons within an organization conduct themselves accordingly, it is essential for the administrators to consider the unique psychological factors that influence employees within their organization.

The main psychological factors that this study will consider are motivation, attitude, and perception. By evaluating each of the psychological factors independently, it will become apparent that psychological factors play an integral role in influencing employee behavior, and thus their likelihood to follow ethical and compliance guidelines. However, before getting into detail about the essence of considering psychological factors when adopting ethics and compliance guidelines, it is important to evaluate what makes up good ethics and compliance guidelines.

Many business organizations exist as several units that combine together to work towards a common goal (Saracho, 2019). Therefore, they rely on centralized and coordinated approaches that allow the distinct units to operate together in unity so as to achieve the objectives of their organization. Ideally, the centralized governing guidelines are generated by the management in conjunction with some of the operational managers and committee members to address the unique challenges experienced by the organization in its attempt to deliver on its mission and to achieve its predetermined goals (Yushi et al., 2018).

Although the ethics and compliance guidelines are intended to help businesses stay on course as they accomplish their goals, present occurrences indicate the need for better-refined ethics and compliance measures. That is because there is currently a trend of increasing litigations among administrative professionals all over the globe (Tamir \& Thornton, 2018). The lawsuits have directly translated 
into criminal cases, publicized internal and external investigations, as well as penalties for business organizations. Because the ethics and compliance violation cases have resulted in significant media attention, the reputations of a lot of countries have suffered, resulting in significant damages to their revenue collection as well as public relations.

Given that the present is an age when businesses are doing their best to scale up operations, compliance with ethical and operational guidelines is paramount. That is because as companies expand the scope of their operations, they get into a new jurisdiction, some of them stricter than others (Yushi et al., 2018). Therefore, if business wishes to remain sustainable and expand their activities, they must comply with corporate ethics and guidelines which must form the foundation of their operations.

However, it is pertinent to consider the influence of psychological factors on compliance. Provided employees do not follow the operational guidelines, it does not matter how well an organization structures its ethics and compliance guidelines. They must ensure that the guidelines are simple for employees to follow, since that will influence their ability to comply and avoid legal and reputational issues that could significantly impact their activities.

\section{Methodology}

The study will take a qualitative approach. That is because it will rely on descriptive and non-numerical data in the formulation of its findings. The study will aim to be exploratory because it will rely on secondary literature to develop its findings. For validity reasons, the research will only focus on scholarly articles that are from within the past five years. The business world has significantly evolved in the recent past, and it will be pertinent to rely on studies that give an accurate picture of the present. As such, the research will rely on existing data for its data collection activities.

Data analysis will take place through content and thematic analysis. In content analysis, it will be important to understand the meaning of the different psychological factors essential in determining human behavior within an organizational context. The thematic analysis will play a major role in showing how the different psychological factors may cause employees and other stakeholders within an organization to either comply or fail to follow the rules and guidelines that govern human behavior.

\section{Psychological Factors to Be Considered}

\subsection{Motivation}

Motivation is an essential ingredient in promoting compliance with ethical and operational guidelines. Ideally, motivation is a process associated with the development of traits that allow an individual to be goal oriented (Tamir \& Thornton, 2018). Because of motivation, it becomes easier for individuals to persevere through hardships as they target to achieve their goals. Considering that 
not all behaviors associated with ethics and compliance guidelines may be appealing, it is essential that employees are maintained on track through motivation.

For instance, employees may have to choose between swindling finances from their organization or following finance ethics to report all transactions. The first option is the more lucrative option and provided employees do not get any motivation to keep their actions in check, they may act contrary to the expectations of their employer.

All human actions are controlled by motivation and the psychological concept does a wonderful job explaining why people behave in particular ways. It is controlled by emotional, social, cognitive, and biological factors (Wallston \& Wallston, 2020). For instance, the desire to feed (a biological need) compels people to go to work so that they can earn a living. In an organizational context, bonuses and allowances may give employees the incentive to follow ethical and compliance guidelines, since their motivation is stimulated by the financial benefits associated with pursuing the right course of action.

Aside from looking at motivation as a psychological factor that compels people to act in specific ways, it is pertinent to look at motivation as psychological factor that enables people to focus on a specific goal (Yushi et al., 2018). However, unlike the motivating factors that compel individuals to initiate a particular behavior, it is difficult to observe the motivating factors that keep individuals engaged in an activity. For instance, the desire to quench one's basic physiological needs may cause an individual to engage in a vocation. However, it may be difficult to assess the underlying factors that ensure the individual continues to work.

Therefore, when considering motivation as one of the main psychological factors influencing adherence to ethics and compliance guidelines, it is imperative to consider both the motivational factors that will compel the employees to act in particular ways, as well as those that will keep their behavior consistent. In order to develop a better understanding of the factors that affect motivation, the research keenly focuses on psychological theories such as the drive reduction theory, Maslow's hierarchy of needs, and instinct theory.

1) Drive reduction theory

Starting with the drive reduction theory, it was developed by behaviorist Clark Hull, and popularized by his assistant Kenneth Spence (Yushi et al., 2018). The theory was developed in the 1940s, and its objective was to explain patterns of behavior, motivation and learning in human beings. The drive theory postulates that human behavior is controlled by drive reduction. Although the theory once played an important role in explaining motivation, it is deprecated at the moment, and as such, it will not get a lot of attention in the study. However, addressing the drive theory is essential since helps in the understanding of the other psychological theories explaining motivation.

Clark Hull is an iconic behaviorist in history since he was among the first to 
attempt to create a grand theory that explains all aspects of human behavior. His ideas drew from the ideas of other prominent thinkers such as Charles Darwin, Edward Thorndike, and Ivan Pavlov (O'Reilly, 2020). Ideally, a significant portion of his work drew from the concept of homeostasis, which indicates that the human body tends to stay in a state of equilibrium.

For instance, thermoregulation in the body happens in order to avoid the temperatures from becoming too hot or too cold. Therefore, the same way that homeostasis functioned is the same way that Clark Hull believed human behavior to function. According to his theory, drive is a concept that controls human behavior since it reflects psychological needs (Yushi et al., 2018). For persons to control their drives, it is necessary to submit to the psychological needs that are causing the drive.

At the same time, Hull believed that human behavior is influenced by conditioning and reinforcement (O'Reilly, 2020). When an individual gets a reduction in drive after engaging in a particular behavior, then it is likely that they will engage in the same activity again in the future. Essentially, reduction acts as a reinforcement for particular behaviors. Therefore, in order to create effective ethics and compliance guidelines, it is pertinent to consider behaviors that will be fulfilling to the employees. Different from reinforcement, punishment discourages certain deeds (Yushi et al., 2018). Therefore, the use of punitive measures will ensure that persons keep away from improper conduct.

2) Maslow's hierarchy of needs

The Maslow's hierarchy of needs refers to a motivational theory developed by psychologist Abraham Maslow in 1943 (Noltemeyer et al., 2021). According to the theory, people are more compelled to fulfil their basic needs before they move on to fulfil advanced needs. Ideally, the theory purports that humans have an innate desire to self-actualize, but it is pertinent for them to address their most basic of needs before they can tackle complex needs and desires (Gopalan et al., 2017). Self-actualization refers to becoming who an individual is meant to become. However, before self-actualizing, it is imperative to take care of basic needs.

Maslow's hierarchy of needs has five levels of needs, with the most basic level being known as physiological needs. The physiological needs essentially refer to the needs that are critical for human survival. For instance, the needs include food, shelter, and clothing (Gopalan et al., 2017). Once an individual has satisfied their most basic of needs, then they can direct their energies towards other activities. The second level of needs is associated with security and safety. That is because people need to develop financial security as well as attain healthy and constructive lifestyles before they can focus on higher levels of needs.

For business organizations, it is important to supply employees with the basic needs in Maslow's hierarchy to ensure that they abide by the ethics and compliance guidelines. If employees have meager salaries that are incapable of addressing their financial needs, then it is probable that they may swindle their 
employer's resources to cover their basic needs.

In addition to competitive salaries, employees may require comprehensive medical insurance programs as well as insurance plans to ensure they are financially secure once they are no longer in unison with their employer. That is because once the employees are capable of accessing the most essential of needs, then they will direct their energies in ways that are likely to be beneficial to their employers.

Take for example a company that addresses the two most basic needs as per Maslow's hierarchy of needs. Such an organization will ensure that the employees have the most basic of needs, in addition to comprehensive healthcare and retirement packages. With the two most basic needs addressed, employees will focus on higher needs, such as the desire to feel loved, and the desire to improve their esteem (Gopalan et al., 2017). The most important thing to consider is that such needs will improve their ability to exist within organizations and structured environments, since the need for love and belonging will compel the employees to conduct themselves accordingly.

Fulfilling needs at the lower end of the necessity spectrum is important because Maslow's hierarchy of needs talks about deficiency needs and growth needs. The deficiency needs are those at the lower end of the pyramid, and they exist as a product of deprivation (Noltemeyer et al., 2021). Therefore, if persons fail to address the lower levels of needs, they end up unpleasant about their situations, and that may motivate them to engage in crude behaviors as a way of ensuring survival.

When it comes to the growth needs, they do not originate from the lack of essential needs. Instead, the growth needs occur due to the desire of an individual to grow (Saracho, 2019). As such, organizations should leave their employees with the desire for growth, since that will make them more profitable. By addressing all of the basic needs essential to their employees, organizations will ensure that their employees are motivated enough to follow the ethics and compliance guidelines that guide business activities.

3) Instinct theory

The instinct theory is another psychological theory that explains human behavior and could potentially be used to improve obedience to ethics and compliance issues. As per the instinct theory, all living organisms are naturally born with tendencies that improve their chances for survival (Berridge, 2018). The theory indicates that instincts are in charge of determining human behavior. Instincts are natural patterns of behavior, and they are not determined by learning experiences.

An example of instinct in the human species that promotes survival is the tendency of children to seek the nipples of their mothers in search for nourishment. When it comes to birds, some species have to migrate over long distances in search of food or better climate (Bera et al., 2021). The similarity in the above behaviors is that they are hard-wired, and no learning is needed to make organisms capable of accomplishing the deeds. 
According to psychologist William McDougall, instinctive behavior in humans is determined by perception, emotion, and behavior (Bera et al., 2021). In addition to the three essential elements in instinctive behavior, the psychologist also identified 18 distinct instincts that regulate behavior. The instincts include comfort, laughter, sex, food, and maternal instinct (Bera et al., 2021). Psychoanalyst Sigmund Freud also acknowledged the role played by instincts in shaping motivation. That is because he identified the life and death instincts which play a significant role in shaping human behavior.

From the instinct theory, it becomes apparent that behavior is significantly reliant on the biological needs of organisms to survive. As birds move from one region to another in search of better food or climates, they improve their chances of survival. The same applies to infant children as they suckle on their mother's breasts for the first time. Therefore, the instinct theory indicates that organizations should consider the survival of their employees as they develop laws and regulations to govern employee behavior. For instance, ethical regulations that are grounded on the concept of survival may be easier for employees to follow compared to those that are significantly abstract.

\subsection{Attitude}

Organizations also need to pay close attention to attitudes as they develop guidelines to regulate employee behavior. In psychological contexts, attitude refers to a set of beliefs, behaviors, and emotions that influence an individual's predisposition towards a given thing, person, object, or event (Ajzen, 2020). Although attitudes may be unique from individual to individual, they are largely influenced by life experiences and childhood upbringings, which end up having powerful influences on the behavior of an individual. In addition, although attitudes can persist for long periods, they are often malleable and may change depending on an individual's interactions with their direct environments (Yushi et al., 2018).

According to psychologists, attitudes refer to learned tendencies that shape the way individuals evaluate given things. Therefore, attitudes may influence how an individual views others or other objects, and the evaluations may be positive or negative (Yushi et al., 2018). In the event of a business organization, the involved stakeholders may develop either positive or negative attitudes regarding the ethics and compliance policies. If their attitudes are positive, then it is probable that they will influence the stakeholders to abide. However, in the event they are negative, the attitudes may compel individuals not to abide by the ethics and compliance guidelines.

Ideally, there are three components associated with attitude. The first component is associated with cognition. The cognitive features of the mind are deeply associated with thoughts and belief systems (Bera et al., 2021). They are deeply associated with the learning patterns of an individual. Similar to the other two components associated with attitude, the cognitive components can also be formed through a variety of ways. For instance, they can form through expe- 
rience, social factors, conditioning, and learning (Ajzen, 2020).

The second component associated with attitude is the affective component. Ideally, the affective component is interested in the emotions associated with a particular person, event, or object (Yushi et al., 2018). Finally, there is the behavioral component which is largely interested in how the attitudes people have affected their behaviors. In addition, it is pertinent to consider that attitudes can either be implicit or explicit. Explicit attitudes refer to those which individuals are aware of, and they understand how the attitudes affect their behaviors and beliefs (Ajzen, 2020). Different from explicit attitudes, the implicit ones are unconscious, and persons are often oblivious to their existence, let alone their impact on beliefs and behaviors.

As mentioned, attitude formation can take place in a variety of ways. For starters, they can form from experience. As people engage with things, objects and events, they form better perspectives which end up influencing how they will behave or believe within certain contexts (Yushi et al., 2018). Attitude formation may also be influenced by social factors. Clearly, social factors have a lot of influences on human behavior and perspectives. Social factors such as social roles determine how an individual is expected to act and behave within society. For persons with high social expectations, breaking the rules is often not an option, due to the pressures put on them by society.

Learning is another essential factor in attitude formation. In social contexts, it is possible to learn and develop attitudes in a variety of ways. For instance, people could develop new attitudes as a result of classical conditioning (Ajzen, 2020). That is because it is possible to use learning methods to make people associate a particular attitude to a particular event, person, or thing. For instance, commercial advertisements rely on classical conditioning to ensure their audience develops preference for certain brands. That is because viewers are likely to relate to an object depending on its public portrayal.

Conditioning and observation are also essential in the formulation of attitudes. Different from classical conditioning, operant conditioning is a technique that can be used to influence attitude development (Yushi et al., 2018). Operant conditioning relies on the use of negative relations to discourage a behavior or a belief. For instance, imagine a young individual who has developed a habit of using tobacco. However, whenever the individual smokes, others in his immediate surrounding compel him to move away and they also rebuke his behavior. As such, the negative feedback the individual receives from others around him compel him to stop the negative behavior.

Finally, it is important to assess the impact that observation has on attitude formation. When people observe others around them, they are likely to develop similar perspectives which end up affecting their attitudes (Tamir \& Thornton, 2018). However, observation is mainly influential if the observer admires the individual performing a deed. Attitude formation through the process of observation explains how children develop attitudes from their parents. Be- 
cause children spend significant amounts of time observing the actions and beliefs of their parents, they end up developing similar perspectives and outlooks in their lives.

\subsection{Perception}

The last psychological factor that is of importance is perception. That is because it affects the probability that employees and organizational stakeholders to follow rules. Perception refers to how fast an individual can process the information they interact with (Saracho, 2019). In the event of ethics and compliance guidelines, the ability of employees to interpret the rules and guidelines will impact their willingness to abide. The theory of perception is based on the assumption that an individual's beliefs and perspectives are independent of the thoughts and beliefs of others within their vicinity. In addition, the concept is based on the belief that perceptions are entirely based on the external information available to an individual, and it has nothing to do with attitudes and preconceived notions (Berridge, 2018).

The process of perception takes place through various steps. The first step involves the perception of objects as they are present in the real world (Saracho, 2019). After a person interacts with external objects, they perform observations which enable them to internalize the information to better effect. During the internalization process, persons organize the objects in their vicinity depending on their perceptions. As such, it means that it is possible for two people to have distinct perceptions of the same object or event since perceptions are based on personal understanding. After persons have perceived their environments, they respond.

In the process of perception, there are important concepts pertinent to understand. First, it is essential to analyze the internal factors that are involved in perception. One of the main factors is personality (Saracho, 2019). Personality varies from individual to individual. As such, there are persons who pay close attention to details while there are those who are more focused on the bigger picture. Therefore, it is likely that two people observing the same thing may have different perceptions of the same event.

Motivation is another internal factor that influences perception. That is because people are likely to base their perceptions on the things they need as of the moment (Yushi et al., 2018). Therefore, people will choose to draw connections based on the things that will satisfy their immediate needs, choosing to ignore whatever is irrelevant. Finally, experience also shapes perception (Saracho, 2019). That is because past events and the lessons-learned cause people to develop their perspectives in particular ways. People are more likely to understand things in ways that support their past knowledge compared to ways to challenge their knowledge.

It is also imperative to look at the external factors that influence perception in order to develop a clearer understanding of how it affects human behavior. One 
of the main external factors is size. That is because psychological evidence indicates that people are drawn towards things and objects that are of a larger magnitude (Bera et al., 2021). Intensity is another external factor that influences perception. Intensity may be in terms of brightness or abundance. For instance, when a message is highlighted or when it is continuously relayed to an audience, it causes them to become more perceptive of its meaning. Therefore, it means that people are more likely to understand or appreciate a message if its intensity is high.

Another external factor influencing perception is contrast. Contrast means that the message stands out for the audience (Saracho, 2019). When something stands out in the eyes of the audience, it gets better chances for selection, and such a notion should definitely be used in the development of ethical and compliance guidelines in business organizations. Novelty and familiarity are also of essence when it comes to perception. That is because people favor what appears as new.

\section{Discussion}

Thus far, it is apparent that psychological factors play a major role in the adoption of ethics and compliance programs. The ability of a business organization to follow its ethics and compliance guidelines is essential to avoid legal, financial, and reputational challenges. Considering that psychological factors influence human behavior and the likelihood of abiding by the set guidelines, it is important to ensure that ethics and compliance guidelines are designed with psychological factors in mind.

Through the study, it has become apparent that the most essential psychological factors include motivation, perception, and attitudes. The three are important because they determine whether the human power in an organization will abide by the rules or not. Starting with motivation, it is apparent that conditioning and reinforcement encourage individuals to behave within particular ways. It is necessary to consider conditioning and reinforcement in the adoption of ethics and compliance measures since they will influence the motivation of the people to follow. For behaviors that are inacceptable, organizations should consider punitive measures which will force individuals to abstain.

Maslow's hierarchy of needs will also provide significant relief in the formulation of ethics and compliance guidelines. That is because Maslow's hierarchy of needs addresses the growth, and the deficiency needs which influence human behavior. The deficiency needs are much more demanding than the growth needs, and without access to such needs, it is impossible to survive. Different from the survival needs are the growth needs which are not as essential, but they help individuals in their process of becoming self-actualized.

Therefore, when organizations provide their human power with all their deficiency needs, they leave them empowered and motivated to follow the ethics and compliance guidelines. That is because the growth needs are intended for help- 
ing individual coexist better within their social circles, which becomes easier when they have access to the basic needs. As such, they can pursue self-esteem, love, or acceptance from their social circles, which mainly originates from living in tandem with the existing social guidelines.

Organizations also have to pay keen interest on attitude formation to ensure that their ethics and compliance demands best suit their workforce. From the literature review, it is apparent that attitudes influence behaviors. Therefore, organizations must ensure that attitude formation in their employees takes place in a non-biased manner so as to ensure that they follow their organization's goals and objectives. Without the proper attitudes, employees may develop the notion that ethics and compliance guidelines are tilted against them, while they actually exist for the benefit of the organizations and all their constituents.

Finally, it is imperative to pay attention to both the internal and the external factors that shape perceptions. The concept of perception shows that regardless of how well-structured an organization's ethics and compliance guidelines might be, perception takes place at the individual level, and it is likely that different employees will develop different understanding of the same rules and regulations. Companies have better control over the external influences of perception more than they can control internal influences, and it is essential for them to make the most of what they can control.

\section{Results and Conclusion}

At the onset of the research, a goal was established to prove that psychological factors are essential in the adoption of ethics and compliance programs so as to propose psychological factors that are essential to consider. Thus far, it is apparent that psychological factors are crucial in the adoption and development of ethics and compliance guidelines. That is because psychological factors determine whether individuals will comply with the set standards of operation or not. For all business organizations, ethics and compliance programs are essential because they determine whether a business is operating legally, and whether there is proper management of its assets. In the event of audits or when an unethical behavior becomes public, the competitive advantage of a business may considerably suffer.

Therefore, it is essential that the management pays close attention to the psychological factors that influence human behavior so as to ensure they are always compliant. The study indicates that the three most essential psychological factors for businesses to consider are motivation, perception, and attitudes. That is because the three determine whether the human personnel within a business organization will abide by the preset ethics and compliance guidelines that regulate the nature of their activities. As such, the study concludes that psychological factors are indispensable in the adoption of ethics and compliance programs, and they help organizations determine whether their human personnel will remain obedient. 


\section{Conflicts of Interest}

The author declares no conflicts of interest regarding the publication of this paper.

\section{References}

Ajzen, I. (2020). The Theory of Planned Behavior: Frequently Asked Questions. Human Behavior and Emerging Technologies, 2, 314-324. https://doi.org/10.1002/hbe2.195

Bera, B., Bhattacharjee, S., \& Sengupta, N. (2021). Human Behavior, Trustworthiness, and Attitude during COVID-19 Lockdown in Indian Modern Societal and Cultural Antiquity. Journal of Human Behavior in the Social Environment, 31, 77-96. https://doi.org/10.1080/10911359.2020.1829241

Berridge, K. C. (2018). Evolving Concepts of Emotion and Motivation. Frontiers in Psychology, 9, Article No. 1647. https://doi.org/10.3389/fpsyg.2018.01647

Gopalan, V., Bakar, J. A. A., Zulkifli, A. N., Alwi, A., \& Mat, R. C. (2017). A Review of the Motivation Theories in Learning. AIP Conference Proceedings, 1891, Article No. 020043. https://doi.org/10.1063/1.5005376

Noltemeyer, A., James, A. G., Bush, K., Bergen, D., Barrios, V., \& Patton, J. (2021). The Relationship between Deficiency Needs and Growth Needs: The Continuing Investigation of Maslow's Theory. Child \& Youth Services, 42, 24-42. https://doi.org/10.1080/0145935X.2020.1818558

O’Reilly, R. C. (2020). Unraveling the Mysteries of Motivation. Trends in Cognitive Sciences, 24, 425-434. https://doi.org/10.1016/j.tics.2020.03.001

Saracho, O. N. (2019). Motivation Theories, Theorists, and Theoretical Conceptions. In Contemporary Perspectives on Research in Motivation in Early Childhood Education (21 p.). Information Age Publishing, Inc.

Tamir, D. I., \& Thornton, M. A. (2018). Modeling the Predictive Social Mind. Trends in Cognitive Sciences, 22, 201-212. https://doi.org/10.1016/j.tics.2017.12.005

Wallston, B. S., \& Wallston, K. A. (2020). Social Psychological Models of Health Behavior: An Examination and Integration. In Handbook of Psychology and Health (Vol. IV, pp. 23-53). Routledge. https://doi.org/10.1201/9781003044307-2

Yushi, J., Naqvi, M. H. A., \& Naqvi, M. H. (2018). Using Social Influence Processes and Psychological Factors to Measure Pervasive Adoption of Social Networking Sites: Evidence from Pakistan. Emerging Markets Finance and Trade, 54, 3485-3499.

https://doi.org/10.1080/1540496X.2017.1417834 